\title{
Lightweight Design of Milling Cutter with Modified Stiffness
}

Pavel Hanzl ${ }^{1}$, Vojtěch Rulc ${ }^{2}$, Hynek Purš2, Miroslav Zetek ${ }^{1}$, Ivana Zetková ${ }^{1}$

${ }^{1}$ Regional Technological Institute, Faculty of Mechanical Engineering, University of West Bohemia. Univerzitní 8, 30614 Pilsen. Czech Republic. E-mail: ${ }^{1}$ hanzlp@rti.zcu.cz, ${ }^{4}$ mzetek@rti.zcu.cz, ${ }^{5}$ zetkova@rti.zcu.cz

${ }^{2}$ Advanced Engineering s.r.o. Na Ostrohu 2405/16, 16000 Praha 6. Czech Republic. E-mail: ${ }^{2}$ vrulc@advancedeng.cz, ${ }^{3}$ info@advanced-eng.cz

The conventional milling cutter design is based on a solid body. A cutter designed in this way has a guaranteed rigidity, but at the expense of tool dynamics. Computational methods of designing reduce the mass of a cutter in locations with lower stress density. This approach increases stiffness relative to the weight of the cutter. This paper analyses the benefits of modifications in the design of a lightweight cutter. The design uses an envelope of a conventional milling cutter that is filled by walls. Each modification changes the elasticity in different directions. These changes are monitored by displacements at the centre of the cutting inserts under load. Simulations confirm that even a small weight gain can mean a significant increase in tool stiffness.

Keywords: Milling Tool, Topological Optimization, Direct Melting Laser Sintering, Metal Additive Manufacturing

\section{Introduction}

The development and optimization of cutting tools should result in improved efficiency and increased productivity. This can be done in different ways. Illés et. al [1] published a solution to this issue in conjunction with Industry 4.0. The specific cost and quality assurance are important indicators. In this regard, there is an effort to find an optimal design for cutting tools. However, new geometry requires the tuning of process parameters, which is a very lengthy process. This is illustrated by Kundrát et. al [2]. In their study, the focus was on the comparison of three different commonly used milling inserts regarding cutting forces under different process conditions.

This study is focused on creating a new design for a milling cutter. We used 3D metal printing technology to produce it. Therefore, the whole concept of the cutter takes advantage of Direct Metal Laser Sintering (DMLS) technology, which is one of many technologies used in Metal Additive Manufacturing (MAM).

The advantages of MAM are mainly exploited in the aerospace industries. Precious alloys are used such as titanium alloys or Inconel alloys. An example of one company using this is technology is Space $\mathrm{X}$, which is developing reusable space shuttles. Generally, successful applications of MAM minimize costs and increase part values. Post-machining can be reduced and the geometry of parts can be improved for better part performance, finding optimal functionality with reduced weight.

The design of the cutter should be a trade-off between buildability, costs and quality. Cavities inside the cutter improve production reliability because the residual stress trapped in the material depends (among other things) on the melted cross-section per layer. There are no such demands on the design of support structures when producing a full-solid variant. Due to the smaller cross-sectional area, less heat is introduced into the melted zone and the support structures do not have to transfer as much heat as a full-solid cutter. The residual stress is reduced because the thermal gradient is more moderate and the supports can anchor the cutter less firmly. Up to $80 \%$ of stresses can be removed with heat treatment. [3]

This study summarizes the provisional conclusions of our search for a cutter design which is closest to the ideal shape with respect to the specified conditions. It was carried out by combining a pre-processor ( $\mathrm{Hy}-$ perMesh), and a structural solver (OptiStruct). The use of computer aids such as FEA or modal analysis is common for predicting the behaviour of mechanical parts. [5][6]

\section{Cutter buildability}

The self-supporting angle, which is an aspect of buildability, is related to thermal conductivity. Metal powder is a thermal insulator because of the gas phase between the powder particles. Thermal transmission is limited in this environment. The energy delivered to the melted zone is diverted mainly through the solid material of the part and the supports into the building platform. Less overhanging surfaces are less thermally stressed because they have more solid mass in the lower-layers near their edges (contour) in the current layer. Thus the risk of collision with the recoater is minimized because the edge of contour does not make 
so much effort to deflect above the current melted layer due to residual stress.

Each kind of metal powder has a different safety value for the self-supporting angle. In general, the safety angle is around $40^{\circ}$ to $45^{\circ}$. The whole design accepts the limits of the production technology. The thickness is adapted to the strength requirements and heat transmission. Even a thickness of $1.5 \mathrm{~mm}$ could be sufficient for reliable production. However, due to the strength requirements, its value was set at $2.5 \mathrm{~mm}$.

The lower weight than the solid cutter will allow a decrease of the inertia force and modify the stiffness along the radial and axial axes of cutter. Additionally, the weight saving reduces the cost per cutter.

\section{Model design and boundary conditions}

The models of the variants retain the outer shell of the standard milling cutter. This design is clear and practical because the shape consists of smooth surfaces without cavities. Therefore, the chips do not stick to the cutter body and generally the chip control is better. The cavities into the cutter are divided into clusters by bulkheads with the same thickness as the shell. A cooling channel is embedded into these bulkheads. There are cooling inserts from the rake and flank side. This cooling method increases the durability of the cutting edges of the round insert. The cooling system is shown in Figure 1.

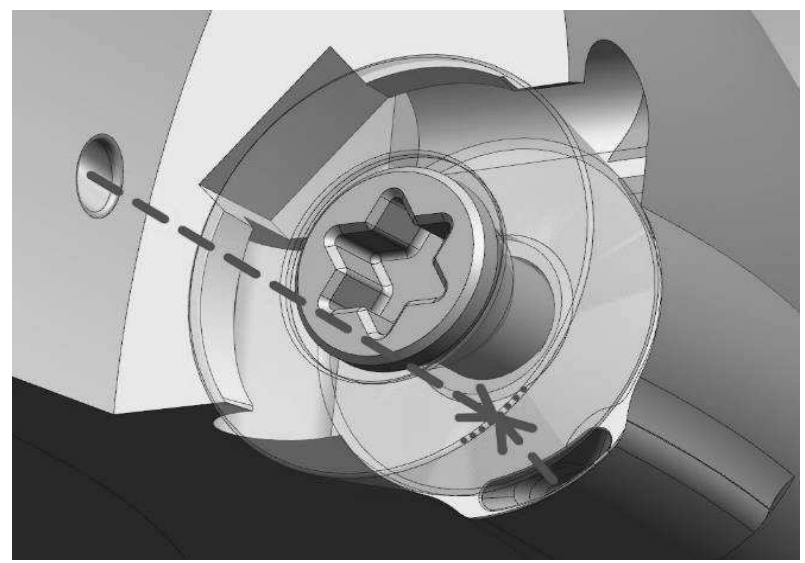

Fig. 1 Internal coolant channels for more efficient milling process. Path of liquid is highlighted by dashed line, the round insert is displayed transparently

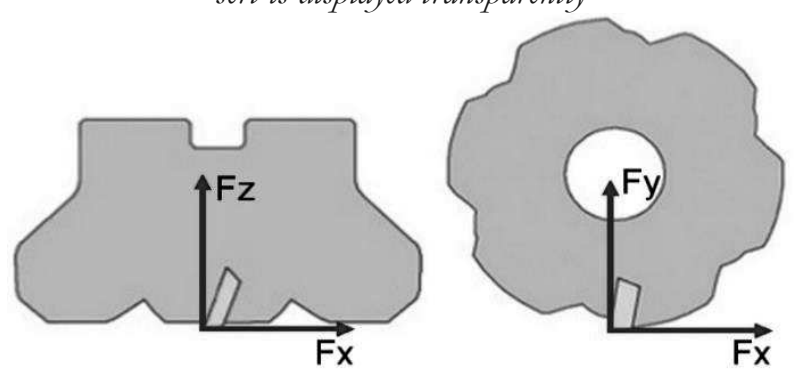

Fig. 2 Designation of force components acting on the cutter body

A bulkhead is oriented across each cluster. This orientation is inspired by the direction of the cutting force components in plane XY, which were experimentally obtained with predefined cutting conditions. The orientation of bulkheads are not completely collinear with the cutting force. The bulkheads are situated closer to the axis and are collinear with axis $\mathrm{Z}$.

The entire design of the cutter is made from tool steel 1.2709 (European classification) and the machine EOS M 290 is used for production. The mechanical properties for this material are the modulus of elasticity $(210 \mathrm{GPa})$, Poisson ratio $(0.3)$ and the density $(7850 \mathrm{~kg} \cdot \mathrm{m}-3)$.

The boundary conditions such as force components are set based on experimental measurements of a solid cutter with the same geometry. Two of the six inserts were always under full load during the simulation.

The value of the safety factor $(\mathrm{SF}=2)$ was chosen based on a rule of thumb to compensate for the difference between the dynamic character of a real load on the milling cutter and the static load of the simplistic model which is analysed. It is important to say that the dynamic effects are covered just by these measurements and SF, so the simplification by converting the case into a static one should be fully adequate. After this, the force components are set as follows: $\mathrm{Fx}=980$ $\mathrm{N}, \mathrm{Fy}_{\mathrm{y}}=550 \mathrm{~N}$ and $\mathrm{Fz}=660 \mathrm{~N}$ (see Figure 2, image modified from Sandvik).

\section{Variant A}

This variant is the default state for the modification. The perforation of the bulkheads allows the emptying of the powder from the enclosed space, and its geometry will be changed after finite element analysis. The original geometry is shown in Figure 3. The thickness of the bulkheads is constant.

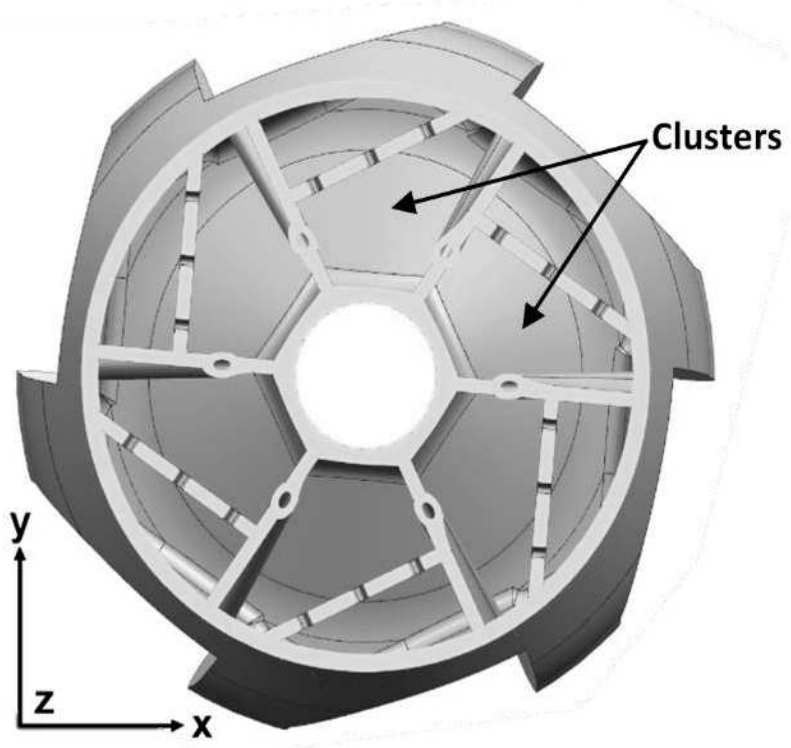

a) 


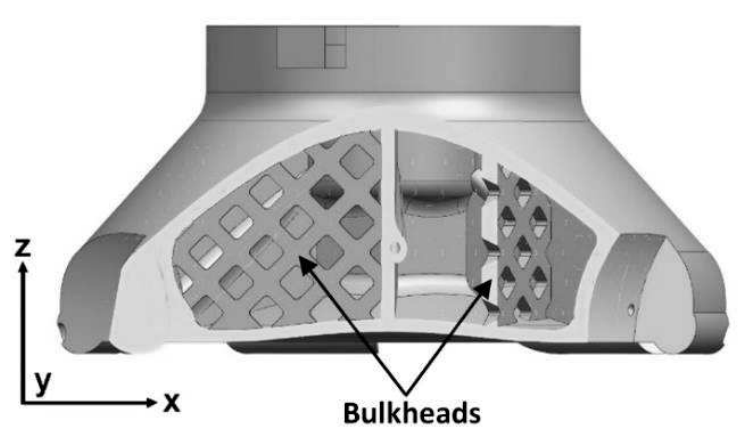

b)

Fig. 3 Section of V ariant A. a) Cluster distribution of lightweight cutter. b) Detail of perforation of bulkheads

\section{Variant B}

This variant has reinforced bulkheads. Jia and Li [6] published research on the topic of bulkhead reinforced. The main solution is reinforced a topology of strukture in the most loaded direction. Therefore the struts along the direction from the inserts to the shell are strengthened. Figure 4 shows how this is done. This solution is about 3\% heavier than A.

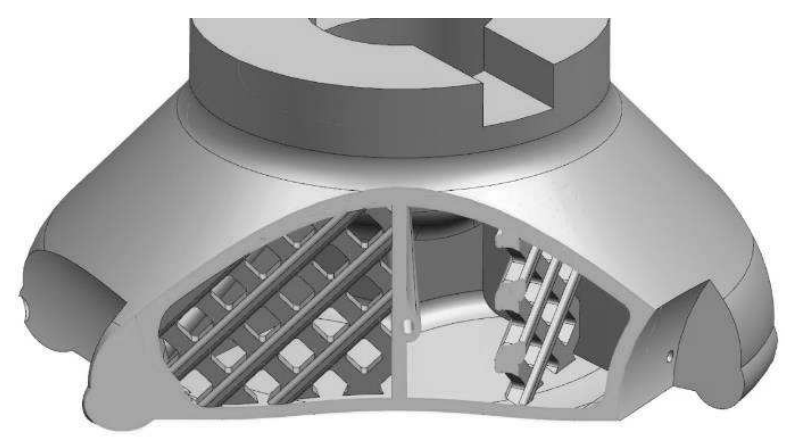

Fig. 4 Section of V ariant $B$, the bulkheads have variable thickness for higher strength

\section{Variant C}

Variant $\mathrm{C}$ adds material to the outer shell of the cutter at the transition between the clamping portion and the outer cone. This increases the weight by an additional $4 \%$.

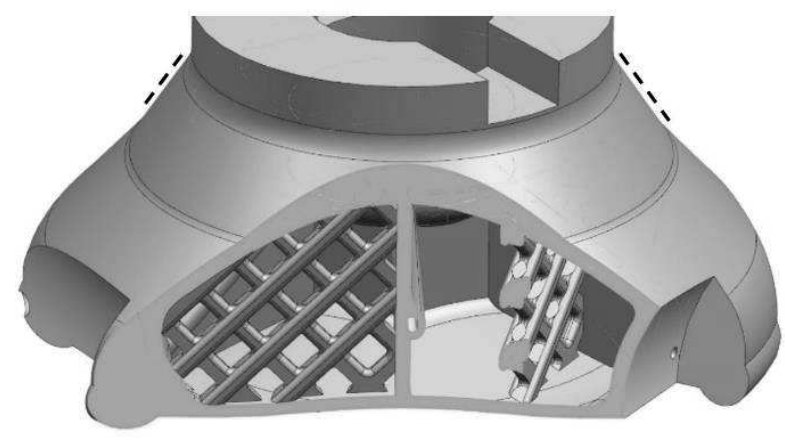

Fig. 5 Reinforced transition between clamping part and outer surface of cutter (see zone of dashed line)

\section{Variant with lattice structure}

This variant deserves only for comparison with preciously provided research which was published in paper [4]. Lattice version has lower stiffness but better damping properties.

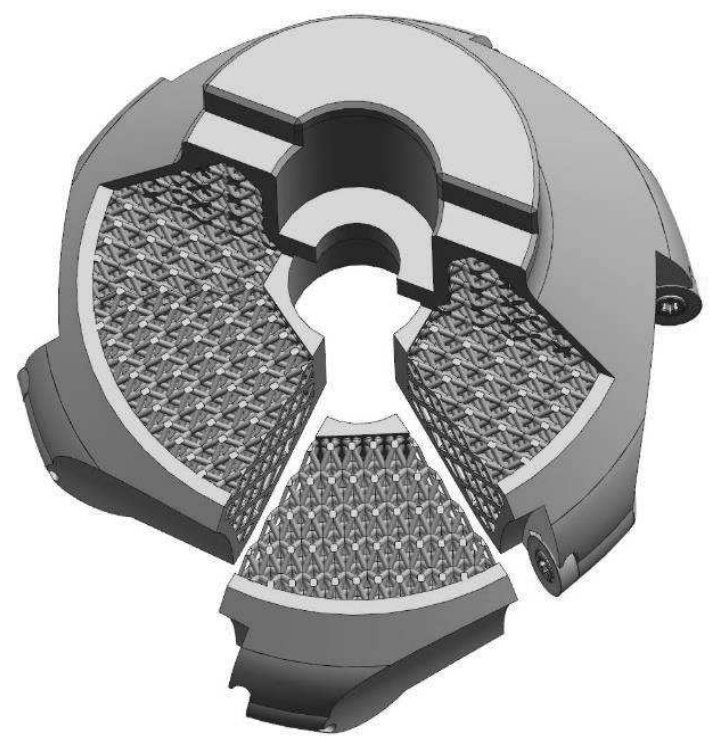

Fig. 6 Section of Lattice variant, a segment of one cluster is excluded from cutter

\section{Results and discussion}

Solid and lattice versions of the cutter are compared here. The publication [4] is dedicated to this milling cutter with implementation of the modified BCC lattice structure. The results are given in Table 1. The conditional colour formatting highlights the comparable values (e.g. the axial value for all variants of load case 1, etc.). The disposition of the load cases from FEA is shown in Figure 7 and the computed stress fields are shown in Figure 8.

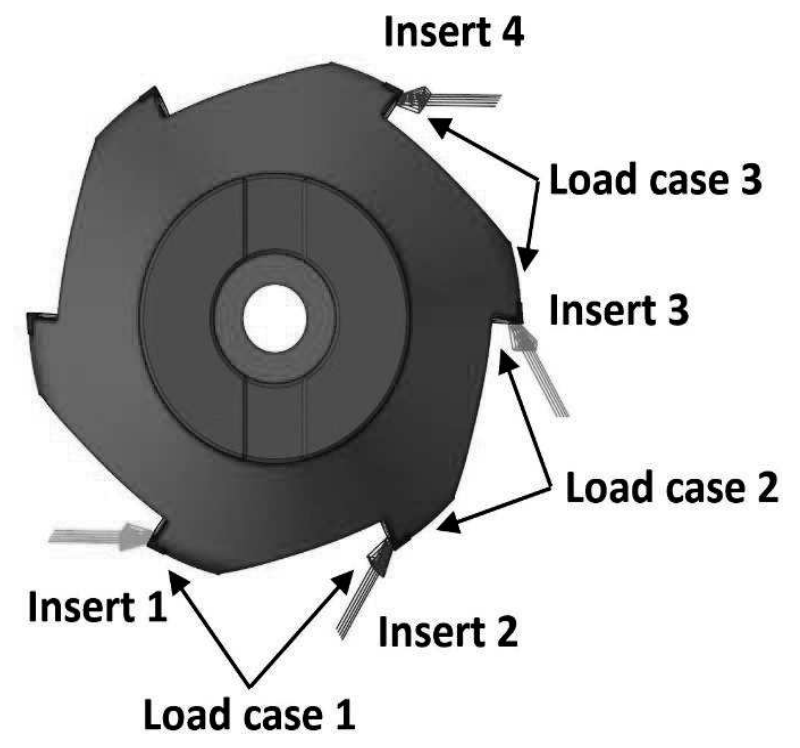

Fig. 7 Load cases and insertpositions of FE $A$ 
Tab. 1 List of measured displacements at the centre of the screws which hold the round inserts

\begin{tabular}{|c|c|c|c|c|c|c|c|c|c|c|}
\hline \multirow{2}{*}{ Model } & \multirow{2}{*}{ Load case } & \multicolumn{2}{|c|}{ Insert position 1} & \multicolumn{2}{|c|}{ Insert position 2} & \multicolumn{2}{|c|}{ Insert position 3} & \multicolumn{2}{|c|}{ Insert position 4} & \multirow{2}{*}{$\begin{array}{c}\text { Weight } \\
{[\mathrm{kg}]}\end{array}$} \\
\hline & & axial & radial & axial & radial & axial & radial & axial & radial & \\
\hline \multirow{3}{*}{$\begin{array}{c}\text { Solid } \\
\text { design }\end{array}$} & 1 & -1.467 & -0.741 & -1.011 & -1.309 & & & & & \multirow{3}{*}{2.74} \\
\hline & 2 & & & -1.409 & -0.873 & -1.052 & -1.146 & & & \\
\hline & 3 & & & & & -1.474 & -0.690 & -1.056 & -1.170 & \\
\hline \multirow{3}{*}{ Variant A } & 1 & -4.709 & -0.131 & -2.291 & -2.320 & & & & & \multirow{3}{*}{1.03} \\
\hline & 2 & & & -4.475 & -0.352 & -1.799 & -2.116 & & & \\
\hline & 3 & & & & & -4.247 & -0.071 & -2.050 & -2.143 & \\
\hline \multirow{3}{*}{ Variant B } & 1 & -3.425 & -0.063 & -1.612 & -1.693 & & & & & \multirow{3}{*}{1.07} \\
\hline & 2 & & & -3.228 & -0.250 & -1.208 & -1.530 & & & \\
\hline & 3 & & & & & -3.031 & 0.023 & -1.416 & -1.540 & \\
\hline \multirow{3}{*}{ Variant C } & 1 & -2.672 & -0.123 & -1.401 & -1.233 & & & & & \multirow{3}{*}{1.11} \\
\hline & 2 & & & -2.484 & -0.309 & -1.018 & -1.088 & & & \\
\hline & 3 & & & & & -2.299 & -0.099 & -1.220 & -1.078 & \\
\hline \multirow{3}{*}{$\begin{array}{l}\text { Lattice } \\
\text { variant }\end{array}$} & 1 & -4.057 & -0.663 & -1.802 & -3.265 & & & & & \multirow{3}{*}{ - } \\
\hline & 2 & & & -4.011 & -0.799 & -1.705 & -3.062 & & & \\
\hline & 3 & & & & & -3.976 & -0.577 & -1.747 & -3.133 & \\
\hline
\end{tabular}

Note: The values are given in $[\mu \mathrm{m}]$.

radial - displacement in the radial direction (the radius change) axial - displacement in the direction of $z$ axis

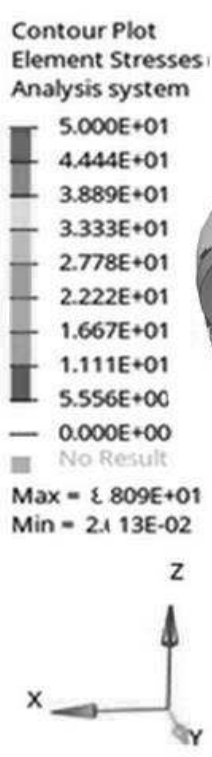

Variant A

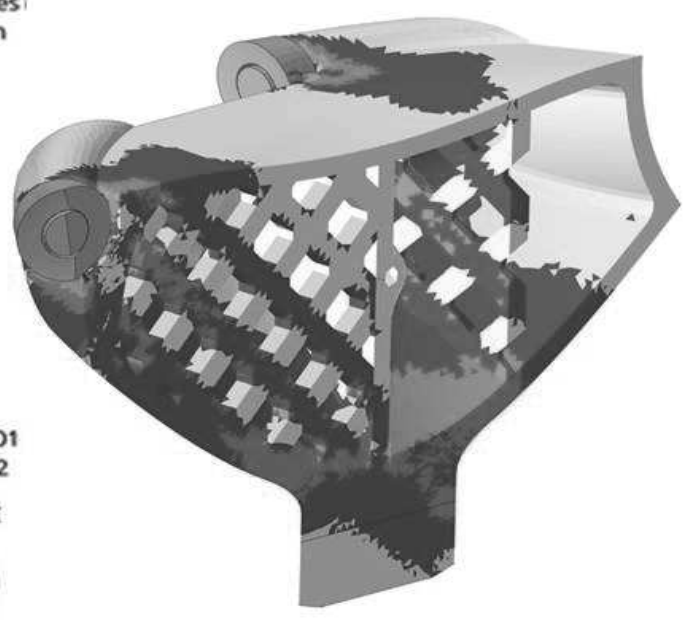

Variant C

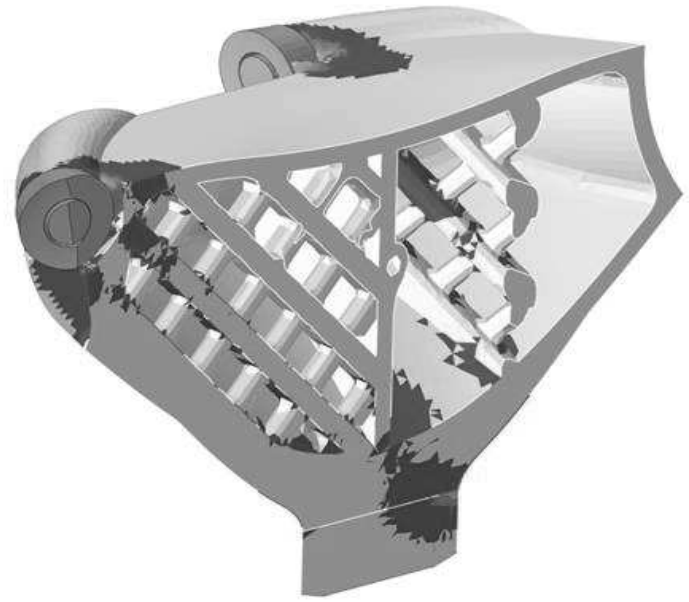

\section{Variant B}

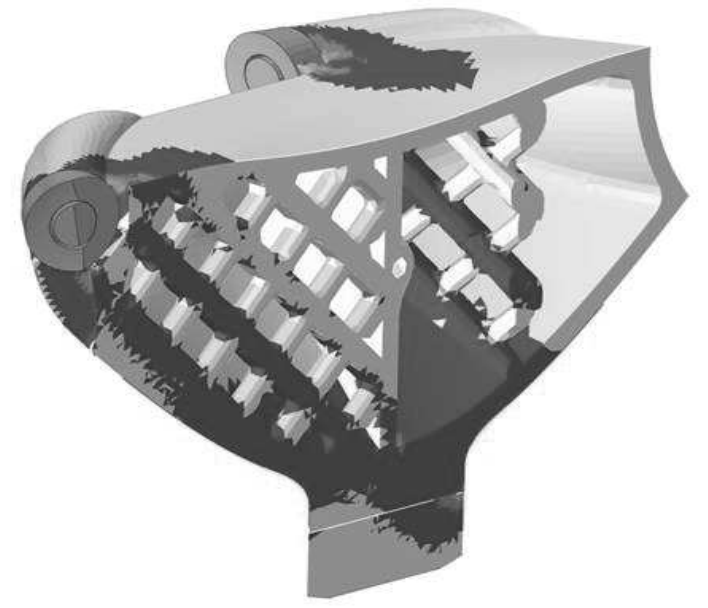

Lattice

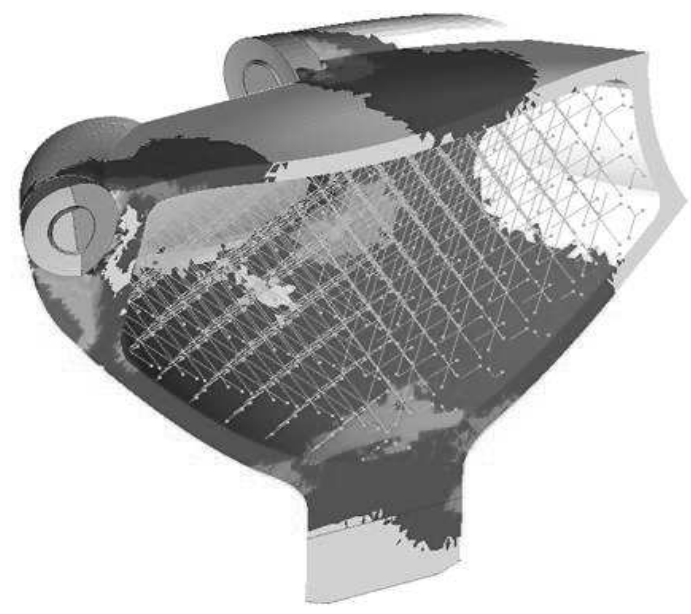

Fig. 8 Stress analyses of different variants for first load case; milling cutters are shown in section 


\section{Conclusion}

The main aim of this research was to perform a static analysis in the linear region of the deformations. The subject of the analysis was a milling cutter that is filled with walls designed for a rotating cutter. The whole concept of this lightweight milling cutter combines manufacturability using MAM and the static load requirements for machining by milling.

- Variant B, with reinforced perforated walls in the direction of stress, was significantly stiffer than variant $A$. The resulting deviations in the radial and axial directions decreased by an average of $35 \%$.

- Variant C, with reinforced grid ribs in the stress direction and greater rounding of the body taper, is stiffer than variant $\mathrm{B}$. The resulting displacement is difficult to summarize due to variation in the different directions.

- Variant B shows a 30\% reduction of the maximum von Mises stress compared to variant
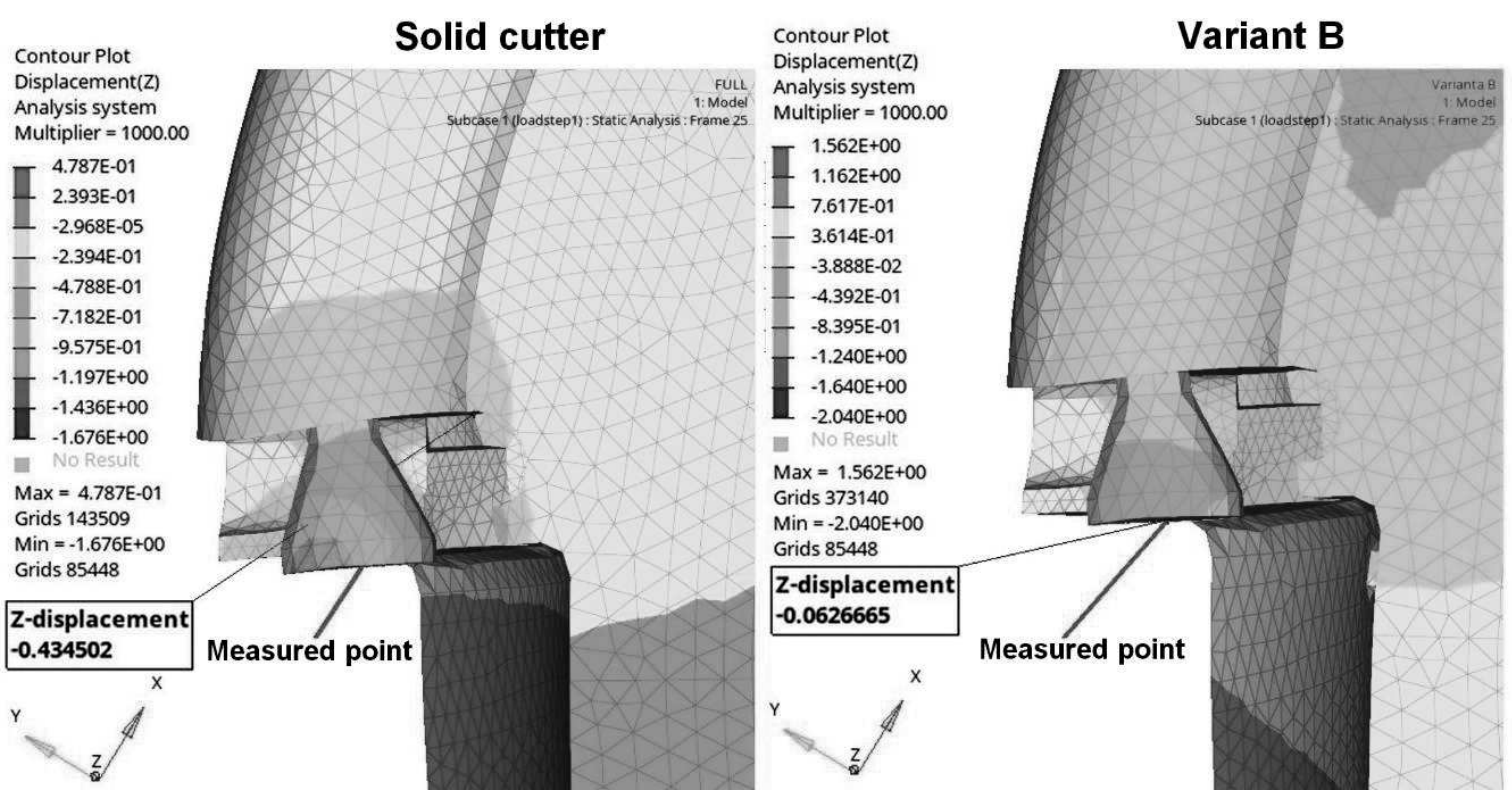

Fig. 9 Unfavourable z-axis deflection for solid cutter

\section{Acknowledgement}

This paper was created with the subsidy of the project TRIO FV30149.

\section{References}

[1] ILLÉS, B., TÁMAS, P., DOBOS, P., SKAPINYECZ, R. (2017) New Challenges for Quality Assurance of Manufacturing Processes in Industry 4.0, Solid State Phenomena, August 2017, Vol. 261, Pp. 481-486
A. Variant $\mathrm{C}$ does not reduce the stress further.

- $\quad 3 \%$ weight increase between variants $\mathrm{A}$ and $\mathrm{B}$ resulted in a $30-35 \%$ improvement in the observed characteristics. A 4\% weight increase between variants $B$ and $C$ led to changes in stiffness directions but not to an average improvement between these variants.

It is also interesting to compare the displacements of the first inserts in the load cases. The inserts of the solid cutter exhibit many times higher deviations than the lightweight variant B (see Figure 9). It should be noted that dynamic phenomena such as centrifugal acceleration are not considered during the static analysis. Subsequent optimization will look for a shape that ensures the best ratio of displacements in the radial and axial axes. In other words, the ideal compromise between the behaviour of the solid variant and variant B. 
[4] HANZL, P., ZETEK, M., RULC, V., PURŠ, H., ZETKOVÁ, I. (2020) Finite Element Analysis of a Lightweight Milling Cutter for Metal Additive Manufacturing, Published by Manufacturing Technology, ISSN 1213-2489, October 2019, Vol. 19, No. 5, Pp. 753-758

[5] VAVRO, J., VAVRO jr., J., KIANICOVÁ, M., VAVROVÁ, A., PECUSSOVÁ, B. (2019) Numerical Modal Analysis of the Turbo-jet Engine
Rotor Blades, Published by Manufacturing Technology, ISSN 1213-2489, December 2019, Vol. 19, No. 6, Pp. 1067-1070

[6] JIA, D., LI, F. (2019) Design of bulkhead reinforcement of trimaran based on topological optimization, Ocean Engineering, ISSN 0029-8018, November 2019, Vol. 191, 106498 